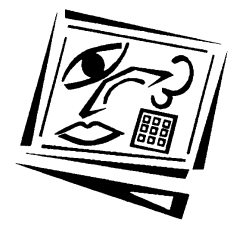

\title{
Case studies: Integrating the use of web based learning systems into student learning
}

\author{
Simon Housego and Mark Freeman \\ University of Technology, Sydney
}

Competitive pressures on universities to adopt flexible learning are intense. Many academics and managers are responding by incorporating web based learning (WBL) tools into the teaching environment. WBL tools have proliferated in recent years, and some can be used to manage entire courses. The simplicity of WBL systems, like WebCT, TopClass and Blackboard, makes their use in teaching an option for many academics, even those operating without institutional support or encouragement.

\begin{abstract}
Academics are seeking meaningful uses of these WBL systems for teaching and learning. The objective of this paper is to describe some meaningful uses with five fictional case studies based on our experiences in innovation and academic development. Our motivation is that academics and academic managers will identify one or more opportunities from the case studies to apply in their own context. Others including Hara and Kling (1999) have identified the need for this research. The case studies show ways in which teaching, learning and administration can be supported, adapted and extended with web based learning systems. Well understood teaching strategies can be improved with simple and easily implemented uses of WBL systems that can benefit on and off campus students. If underpinned by student centred teaching practices, these tools can make significant contributions to the effectiveness of teaching without also imposing an unsustainable demand for resources.
\end{abstract}

\section{Introduction}

The objective of this paper is to address a need identified by Hara \& Kling (1999) for research focussing on teaching strategies that utilise technology for supporting teaching and learning. Five case studies, based on real experiences but with fictional characters, show web based learning (WBL) systems being used to assist students learning in on and off campus situations.

Blackboard, CourseInfo, TopClass and WebCT are examples of the WBL systems in common use in the higher education sector. Our experience 
with the use of WBL systems over five years is that these tools can be used to achieve administrative and learning benefits. Improved productivity or efficiency has been a major motivation for academics incorporating technology in higher education in recent years (Alexander \& McKenzie, 1998). Academics and administrators are trying to cope with increased teaching loads and dwindling resources. Alexander \& McKenzie also identified improved learning outcomes and improved attitudes to learning as high on the agenda in their national study. Achieving such improvements without imposing ever increasing demands on students, on academics, and on the resources necessary for effective student learning, is a challenging goal.

The structure of the paper is as follows. Section 2 reviews the background literature. Section 3 considers the research method. Section 4 presents five case studies of increasing sophistication illustrating integration of WBL for teaching and learning. Section 5 synthesises and interprets the case studies. Section 6 provides conclusions, limitations and possible future directions.

\section{Background literature}

Extensive literature is available to support our views of teaching and learning and good teaching practice, but as Hara \& Kling (1999) have pointed out there is a lack of literature on how technologies like WBL can be used for teaching and learning in line with these views. Most of what is available can be characterised as reports of use. We are seeking to show that uses might vary with differing conceptions of teaching and learning.

\section{Views of teaching and learning}

Our thinking about teaching and learning derives from Marton and Säljö's (1976) research into deep and surface approaches to learning. Many authors have built on this work which argues that "differences in the outcomes of learning in a particular situation were closely related to the ways in which the learner approached that situation" (Bowden and Marton 1998). Surface approaches usually result in short term retention of rote learnt facts. Deep approaches typically result in students changing their understanding in some meaningful way. In their summaries of this research, Prosser \& Trigwell (1999) and Ramsden (1992) shows how variation in student learning outcomes can be explained by the way academics establish a learning context, and the way that students go about learning in that context includes the influence of students' prior experience of learning. 


\section{Good teaching practice}

Biggs (1999a) provides a comprehensive discussion of how a learning environment can be transformed to achieve quality outcomes. A critical component in this transformation is a transition from teacher centred practice to student centred since Trigwell \& Prosser (1998) found the latter were more likely to encourage students to take a deep approach to learning. They describe such teaching as desiring changed conceptions for students rather than as information transmission to students.

Biggs (1999a) describes the importance of alignment in achieving quality learning outcomes. Alignment refers to the integration of teaching and learning activities with assessment practices to achieve the stated curriculum objectives. This can be effective in encouraging students to adopt a deep approach to their learning. Academics who use alignment most effectively are likely to be those with a student centred conception of teaching.

The transition from teacher centred practice, where student learning is seen as a result of what the teacher does, to a student centred practice where student learning occurs as a result of what the student does, is central to Biggs' model. In our opinion it is the most important change that academics must make to achieve most effective use of web based learning systems.

Some academics view students as either capable or not capable of learning and it doesn't particularly matter what the academic does to help the students. These academics would contend that the widening of access to higher education has led to increases in the numbers of students who are not really capable of learning at the required level.

A slightly more optimistic view is held by academics with a transmission model of teaching. For these academics the primary responsibility is to ensure that students get the right information. Academics with this view, when trying to improve their teaching, will seek to improve the quality, variety and richness of their knowledge transmission.

For Biggs, the academics who are most likely to promote effective student learning are those whose views of learning is that "meaning is not imposed or transmitted by direct instruction, but is created by the students' learning activities" (1999a). These students do. With this view of student learning, the distinction between a learning resource and a learning 
activity becomes very clear. Putting lecture notes online (a learning resource) cannot be expected to improve student learning, a result in line with Clark $(1983,1994)$.

The learning activity, and not the technology or medium in which it is used, is the key to improved outcomes. The primary role of the teacher is to create meaningful learning and assessment activities. The way in which web based learning systems are used and the extent to which they are used should be determined by the overall learning design. Alexander \& McKenzie's (1998) review of the population of government funded technology supported projects in higher education in 1994 and 1995, supports the importance of the design of the teaching and learning activity.

Good teaching practice extends beyond alignment of objectives, assessment and learning activities. Without a holistic approach, academics can fail to motivate deep approaches. General principles have a role in promoting student learning through good practice, like Chickering and Ehrmann's (1997) seven principles of good practice in undergraduate education; student-faculty contact, cooperation among students, active learning, prompt feedback, time on task, high expectations and respect for diverse talents and ways of learning.

Motivation, whose absence in students is often lamented, is a product, not a prerequisite, of good teaching (Biggs 1999a). For example, even well aligned subjects can fail to encourage deep approaches if assessment, which affects time on task and expectations, is too burdensome.

\section{Motivating change}

To understand what drives the success or failure of a particular technology introduced to support teaching and learning in the higher education sector, we draw on the literature on the diffusion of innovation. Geoghegan (1996), building on Rogers (1995), distinguishes between early adopters of innovation, and mainstream users.

Rogers (1983) in his discussion of the diffusion of innovation identifies five characteristics that influence the rate of adoption of innovation. These are competitive advantage, observability, trialability, compatibility and complexity. Innovation in higher education such as the use of web based learning systems can be interpreted in the light of these factors. 
The motivations of the early adopters of educational innovation in Alexander and McKenzie (1998) can be explained in part by an interest in improving student learning. Mainstream academics are not as easily swayed by this motivation. Their approaches to teaching are influenced by factors additional to theories of teaching and learning. One such factor would be departmental initiatives and incentives aimed at improving the productivity of academics. Institutional procedures and departmental climate and ethos are examples of factors mentioned in Biggs' presageprocess-product model of teaching and learning (Biggs 1999a). Responsibility for these factors normally rests with senior academic managers, for example, by making innovation compatible with current work practices through provision of adequate time and resources. Rogers' model offers a useful lens through which the efforts of those who foster innovation may be viewed.

\section{Research method}

Interpretation of the effects of change in an educational setting can be explored from many different viewpoints. We have chosen to use an educational case study methodology because it provides a way to tell a story and to draw pictures. Bassey (1999) depicts this approach as suited to "narrative stories and descriptive accounts of educational events, projects, programmes, institutions or systems which deserve to be told to interested audiences, after careful analysis. "With sufficient data the researcher is able to carry out a number of tasks including exploration of significant features of the case, creation of plausible interpretations of what is found, and construction of a worthwhile argument or story (Bassey 1999).

In Creswell's (1998) view "the strongest and most scholarly rationale for a (case) study, I believe, follows from a documented need in the literature for increased understanding and dialogue about an issue. Through the case studies we hope to redress a gap in the literature noted by Hara and Kling (1999).

The cases in this paper are fictional but are based on an amalgam of our experiences either directly through our teaching (Freeman 1997, and Freeman \& Capper 1999) or indirectly through anecdotal evidence of teachers in various situations. We are not purporting to describe actual events, nor are we implying that other researchers must necessarily see what we infer. Rather, we seek to portray a range of responses to the challenge of using WBL by teachers with differing conceptions of teaching 
and learning. These portraits are informed by our own experience and we use them to capture many of the challenges faces by adopters of WBL.

Our motivation to proceed in this manner follows Entwistle's (1995) observation that academics are, "naturally, more interested in their own discipline than in concepts introduced by educationalists or social scientists, unless direct connections can be shown between those concepts and their own experience".

In these case studies, academics should find some approach they can apply to their teaching regardless of the context or conception of teaching.

\section{Case studies integrating web based learning systems into teaching and learning}

We present a series of five case studies where WBL systems are integrated into teaching and learning at increasing levels of sophistication. Our aim is to show how WBL can be used to support learning activities in a number of academic contexts, the importance of the academic's role in determining WBL use, and how the use of appropriate assessment strategies can drive student learning. Each case is based on the authors' experiences in using and supporting WBL systems for higher education, although fictitious names are used and some degree of conflation of experiences occurs.

\section{Case 1}

Phil teaches a first year undergraduate subject in a business studies program to 300 students and he is keen to get evidence of effective teaching practice to support his application for promotion to senior lecturer. He is having trouble coping with student numbers in his class, which have climbed in recent years. The greater reliance on the weekly mass lectures has meant students were now sitting for two hours per week in a large lecture theatre for each of the 13 weeks. The international students who make up a third of his class have difficulty studying in a language not their own and Phil is seeking ways to assist them as he knows that their fees help keep him and his colleagues in a job. He wonders if the increasing student numbers include students who aren't really up to tertiary standard. 
Phil is struggling to keep his research program moving and he senses that he's falling behind. He can't afford to spend more time than he already does in helping students. During last semester he was getting about 30 messages a week when he was out of his office from students asking for help. Although he always tried to respond almost immediately, he spent a lot of time leaving voice mail messages. The same questions kept coming up and although he'd answer them at the next lecture, each week brought a new set of frequently asked questions.

Phil's lecture notes need reworking but he hasn't been able to find the time yet. The students always have trouble with the same topics and last semester he ordered some additional books for the library's closed reserve and provided notes with cross references for the students on how these books dealt with the difficult topics. He was dismayed when he found that the books on closed reserve weren't being used.

Several of Phil's colleagues had started to look at using more flexible approaches to teaching and he has heard that some of them are using a WBL tool in their teaching. When discussing this with Phil they described the tool as a web based course management system, which provides academics, and students access to a private web site for coursework with access to private and public message forums. Phil thought this could be a useful learning resource for his students and he decided to try it out. His colleagues suggested that he attend the half day academic development workshop to find out more about the WBL system and some of the simple ways to use it for teaching. Phil commenced using the tool as soon as semester started.

At the end of the semester Phil reflected on his experiences. His understanding of the usefulness of WBL grew as the semester progressed. A show of hands in the first class showed that student access to the web was high enough to justify optional use of the WBL system. Phil hoped that students would see the value in using the WBL system but he didn't quite know how the students would respond and he decided not to make participation assessable. At the start he used it only for important announcements and he encouraged his students to look there before leaving a message on his phone.

At first, students were reluctant to use the announcements forum. When they saw that Phil was conscientious in immediately posting important information there, they began to trust it as the primary source of information. Students quickly saw that they could bypass the waiting 
game that often characterises student-staff interactions out of class. After a while it became apparent to Phil that he could use the same strategy to answer more efficiently the many questions he was asked. He set up a discussion forum for question and answers and announced to students that he'd answer any questions through the Q\&A forum .

Suspecting that the initial experience with the tool would be important for shaping student expectations Phil set up a common login account that any student could use. This 'guest' login was additional to the individual accounts allocated by the university's computer department from the official subject enrolments. He saw the guest login as necessary since there were many changes to enrolments at the start of semester and the guest login would save him the trouble of monitoring which students did not yet have a valid account.

After a slow start the number of questions asked increased rapidly when the students realised that Phil would answer their questions within a day or so. Many students said they found the question and answers valuable for clarifying issues raised in the lectures, and for helping them with their assignments. Several students told Phil they were hesitant to ask questions because they didn't want to show their ignorance. After Phil pointed out that they could use the common account anonymously the number of messages climbed again. Phil kept track of the questions being asked and compiled a Frequently Asked Questions list which he recognised would be a useful resource for next semester's students. The question and answer forum was a great success by the end of semester.

On balance Phil was happy with the outcome. He sensed real value in using the WBL system for supporting the students but also recognised that he could quickly be overwhelmed unless he took a more structured approach. He asked the academic development unit for help with improvements. Their suggestion to use an end of semester student focus group and student evaluation survey was taken up by Phil. The results showed that the students considered that the announcements and Q\&A forums helped them with their learning. A pleasant surprise for Phil was that students who spoke English as a second language really appreciated the guest account for asking questions and made extensive use of it. Students rated his overall teaching more highly than his previous experiences, which he found especially pleasing because the ratings had been trending downwards slowly as class sizes increased. Phil knew that this evidence of an improvement in his teaching would give a welcome boost to his chances for promotion. 


\section{Case 2}

Over the summer break Phil had come up with several ideas for saving him and his students time and effort. He learnt how to add his lecture notes to the growing number of resources that he was making available for his students on the web. He was relieved to find that he didn't have to devote a lot of time to learning how to do this. His new skills came in use for creating a number of supplementary pages with active links to some of the excellent web sites mentioned in the professional journals and newsletters that he read.

When Phil had asked students in the end of semester focus groups about using web based lecture notes, a clear preference for paper notes was expressed, and these were handed out at the start of semester. He no longer needed to provide replacement copies in the library's closed reserve when the original ones were stolen as he could direct students to the web based version. Another source of continual irritation for him and the students - the disappearance of past exam papers and answers - was removed by posting them on the subject's web site provided by the WBL system. As the semester progressed Phil noticed a big increase in the number of students using email to ask him questions privately. Most students now had access to networked computers at home and on campus and they seemed comfortable with email and using the web. As he couldn't afford the time to respond to both private email and the web Q\&A forum, Phil told the students that the most reliable and quickest way to get an answer was to use the public discussion forum on the WBL system.

Jenny, a colleague teaching a related subject, had approached Phil at the start of semester to see if she could observe how Phil used the web discussion forums. She was considering use of a web based component in her own teaching but wanted to have a closer look first. Phil was happy to give Jenny a login to the WBL system. Jenny had offered to make suggestions, particularly for the shorter face to face tutorials (now one hour instead of two) which were not very effective because students did not prepare for them. Phil discussed his suggestions for improving tutorials with her and the tutors.

Each week a structured question relating to current lecture material would be posted into each tutorial group's discussion forum. During the following week students were asked to make a response. With more time to compose their replies they expected the quality of the student responses 
to improve. As the final exam was based on the tutorial topics they decided to grant $5 \%$ of the subject mark for regular participants. Phil's impression at the end of semester was that this worked reasonably well but in future a stronger link to assessment would be needed if participation was to be improved. He noticed that in a face to face tutorial it was easier to pursue students into more qualitative analysis and that in the online tutorials he would need to be more explicit about what students would need to do. Working out who qualified for the $5 \%$ participation mark was much harder than he expected and he spent a lot of time counting up messages.

Another innovative learning activity that Phil tried was topic tracking, which started in the second week of lectures. One of the subject objectives stated that students were expected to understand the relevance of the lecture topics to their discipline area and Phil thought that a topic tracking exercise would accomplish this. Students working in groups, were allocated one of the 12 lecture topics and during the semester they collected reports from a variety of sources including the press and the web and built a set of resources on their topic in their group's discussion folder. Each group could see the other groups' work.

Organising the groups took longer than expected. Some groups complained that others were using resources that they had found, and many groups complained that some group members were not contributing. Phil wasn't quite sure how to deal with this and he decided that it probably didn't matter that much. He guessed that students looking at other students' work would contribute in some way to their understanding. He remembered from his own student days that he'd often picked up valuable information from his fellow students. The number and frequency of contributions determined the 5\% assessment awarded for participation. It took Phil several hours to go through all of the group's resources and he was quite pleased by how most groups had approached the task.

Reflecting with Jenny and the tutors at the end of the year Phil felt justified in trying these new activities with his students. Student feedback, something he automatically requested now, was more positive than in the previous year's survey. He had noticed an improvement in exam results, in that more students seemed to understand the more practical aspects of the subject, particularly among the international students who had become regular participants in the web based discussion forums for tutorials, topic 
tracking and general Q \& A. Some students were still not making use of the extra resources Phil had provided as hyperlinks and it was clear that he needed to provide more compelling reasons for participating by directly linking such learning activities to assessment.

\section{Case 3}

Jenny's observation of Phil's activities was inspired by some of the feedback that Phil had shown her. She was keen to raise the interest level in her second year subject and was aware that it would help her promotion prospects if she succeeded. When she started at the university Jenny had participated in an academic development program that focused on teaching and learning. With some surprise she learnt that no single approach to teaching was best and she had been looking for some time for a way to try something different to conventional lectures and tutorials.

Following Phil's approach Jenny set up a series of web based discussion forums on a variety of issues and topics. She also included a feedback forum for student comments on any aspect relating to the course, a question and answer forum for general clarification, and a social chat forum for anything not relating to the subject material.

The WBL system they used at the university had a multiple choice quiz feature. Quizzes were widely used in teaching in her discipline area. Although Jenny knew that writing a good question could take a lot of time she saw that the questions, once written, could be reused each semester. The ability to provide feedback on answers would solve one of the longstanding criticisms of multiple choice questions. By setting a time period of two weeks following the lecture for taking the quiz she hoped to encourage students to engage with the learning material in a timely fashion. As it was not possible to know who's hands were on the keyboard Jenny decided against using the results for summative assessment, but the feedback students gained when taking the quizzes would be valuable formative assessment. With the quizzes being optional she did not have to worry about disruption to the students if they encountered network problems. They could just try again later. Knowing that similar questions would be on the exam she felt that students would be keen to make use of this learning resource.

Jenny had discussed the topic tracking exercise with Phil and she adapted it for use in her subject, making it compulsory. Graduates from the course 
were expected to be proficient in the use of information technologies, able to work in teams, and possess critical thinking skills. By linking the topic tracking activity to these subject objectives she hoped students would see the relevance of this learning activity. Concerned at the increase in the work she was asking of students, Jenny replaced the mid term assignment worth $30 \%$ with a report from each group on the topic tracking exercise. Due at the end of semester, the report was a short description of the process they employed when building their resource collection and a critical analysis of the their product.

Later in semester, when marking the reports, the tutors were impressed at how creative the groups were and they confirmed Jenny's expectations that a well designed assessment task would make plagiarism difficult, reporting that each group's resources and report were quite distinctive. For Jenny, the key revelation was that she and the tutors didn't have to read each extensive collection of resources to determine each group's mark. The group reports summarised everything for them. Contributions to the topic tracking folders were date stamped on posting and Jenny could easily determine how active the groups were.

In the end of semester survey students rated the topic tracking exercise very well. They welcomed the replacement of the mid term assignment and although the time they spent on the task was much greater, they could spread it across semester. Some students commented that they thought they were being asked to do too much and that they thought the teacher's role was to collect the resources. Jenny realised that she would need to do more in future to prepare her students for this exercise by explaining more clearly how the task related to achieving the subject objectives. Some students complained that other group members had not made an equal contribution but received equivalent marks for the task. Jenny felt that this side effect was bearable given the benefits to the overwhelming majority who did not free ride on their peers.

\section{Case 4}

Mike had joined the department from another university and had a lot of experience with flexible learning. He was hoping for promotion to a senior academic position within the department and was looking for an opportunity to act as mentor to an interested colleague. His appointment was timely for Sophie, who hoped to draw on his experiences with flexible learning innovations. Sophie, who felt that she strongly identified with 
students, was keen to do some pedagogical research in the context of improving her teaching.

Mike and Sophie spent considerable time discussing teaching and assessment as Sophie prepared for her subject, a third year elective with about a hundred students. She was a little puzzled at first when Mike was so interested in the assessment tasks for the subject.

Sophie had agreed, in response to Mike's questions on the issue, that students were preoccupied with assessment, always asking about the exam. To help develop a common understanding of the complex issue of assessment Mike asked Sophie to read Biggs' (1999b) paper on using assessment to drive student learning. Sophie found the paper's discussion of teaching and learning activities very useful for her thinking and felt that she really understood for the first time how powerful a tool assessment was for motivating students to take a deep approach to their learning. Biggs called this alignment and Mike and Sophie agreed that her assessment tasks would be developed on this basis.

Mike asked Sophie to review the subject objectives. Sophie felt that the current objectives were not very explicit and dealt more with the knowledge of the subject than the application of that knowledge. Mike suggested that the course objectives, which in theory applied to all subjects in the program, should be the starting point for a rewrite of the subject objectives. Sophie's revised subject objectives provided scope for assessment activities that required students to demonstrate not only the knowledge of the subject but relevant capabilities and values that accorded with their university's broad objectives for graduates with skills for lifelong learning, ability to use technology, communicate effectively and so on.

One of their colleagues asked if they would be using video recordings of their lectures, which seemed like a great way to help students who didn't want to come to lectures. Sophie said that they wouldn't and she explained why. Biggs' paper had made it easy for Sophie to see that this would be a learning resource. Ignoring the technical hurdles that students would face such as limited network access and inadequate computers for watching web based video, a videoed lecture was still just a passive learning resource. She knew that students needed to do something with any learning resource before learning would occur. Her job was to design learning activities that would engage such motivated action. 
Sophie decided to use web based discussion forums in a similar way to her colleagues Jenny and Phil. Sophie knew that many students found these forums to be useful, but she could now recognise that the forums were best seen as learning resources. Her challenge as a teacher was to go beyond providing web based learning resources and develop web based teaching and learning activities that would be engaging. Sophie used Paulsen's (1995) paper on web based teaching and learning activities as a source of ideas. While there was some real gems in this paper, she felt the need for more detail of 'how to actually do it'.

The major innovation she introduced was a web based debate that she had heard a visiting colleague describe. Students would post a written submission representing their allocated perspective, to be followed on a later day by the alternative perspective. Implementing this would be easy with the WBL system that the university used. The suggestions the visiting colleague provided to Sophie on how the debate could be run were based on his student's feedback on a web debate. She decided that the potential learning would require considerable effort by students. The online, asynchronous, group aspects of the debate were new experiences bringing new difficulties and students would need motivation to overcome them. For these reasons, this warranted the debate being a significant component $(20 \%)$ of the assessment marks for the subject.

Students welcomed the opportunity to discuss their responses in a team and having more time to reflect and research than for a face to face debate. Students from non-English speaking backgrounds appreciated being able to check spelling and grammar carefully before posting their response.

Sophie designed the debates to promote critical thinking and to improve communication and teamwork skills that she had written into the revised subject objectives. The debate topics were based on material that would be covered during the first half of the semester. Careful setup of the debate forums made it harder for cheating to occur because each debate group had access only to their one debate forum. An additional assessment requirement for the debate reinforced individual effort. This comprised a report by each student that gave details of how they had contributed to the debate, what they had learnt from the debate and how this related to the subject and course objectives.

Mike had used a system of self and peer assessment of each group member's effort for group work in his previous job. The system had been 
installed on a departmental sever at Mike's request. He was keen to help Sophie implement it for her group work assessment tasks. The self and peer assessment program enabled students in a group to anonymously rate the contribution of their peers and these ratings would be combined into a factor for adjusting a group mark into an individual mark (Goldfinch, 1993). There were always some students who would not contribute equitably to group work and traditional assessment approaches made it difficult to penalise these free riders without penalising the group. Significant differences in the individual ratings for group members would indicate a problem with the group dynamics, usually due to free riding. The self and peer assessment system would also help students develop their teamwork skills by allowing students to rate their peers.

Sophie's department required a final exam worth a minimum of $50 \%$ to ensure the individualisation of testing. Sophie increasingly felt that exams, particularly closed book exams, were also a certain way to encourage practices characteristic of surface approaches to learning, such as rote memorisation. Changing faculty policy on a central issue like this was outside the scope of the task she'd set herself. She did, however, make the exam 'open book', which would be welcomed by students even though they knew that this would make the exam no easier.

The revision of subject objectives, the introduction of the debate as a learning and assessment task, the use of the self and peer assessment system, and the introduction of an open book exam represented significant changes to the subject. Sophie knew that without the guidance and encouragement from Mike and the departmental resources available that these changes would not have been possible.

Despite some initial problems with students not being clear on what was expected of them in these new learning activities, the feedback from students was very positive. They reacted very positively to the web based learning tasks and self and peer assessment system. On marking the exams papers, Sophie felt that the more positive attitudes and engaging learning activities had resulted in better essays. She resolved that she could still improve things for students by providing clearer guidance on how the web based assessment tasks would work. She decided to take up the suggestion by one student in a focus group and provide an exemplar debate from a previous year in the WBL system for the next student cohort. 


\section{Case 5}

Helen had been given a reduction by half in her teaching load because of a faculty workload policy, designed to encourage innovation. With the promise of teaching the subject for the next 3 years she had a strong incentive to introduce efficiencies in her adaptation of a 3rd year accounting major subject for flexible learning. She intended to use the time saved following the first year's development and implementation, by furthering her research. Her adviser from the academic development unit had suggested that she be diligent in evaluating the changes, not just for evaluation purposes, but also because her experiences could be published. She offered to help Helen do so. Helen considered pedagogical research a bonus outcome.

Her supportive department head confirmed that every hour of face to face teaching that she replaced with the use of flexible learning resources and strategies would be included in her workload reduction for the next 3 years. He had also agreed that the intellectual property of any product with commercial value developed during the subject conversion would be recognised jointly with her, with the proviso that the department had free use while she remained at the university. Helen was now very keen to start re-engineering the subject.

Helen's approach to teaching had changed significantly during the last few years as a result of reflection on her experiences driven by her dissatisfaction with what she'd been able to achieve in her teaching. Her understanding of the different ways in which students approached learning and the role of the teacher in fostering a deep approach to learning now underpinned her student centred teaching strategies. Helen had used a reflective journal to articulate her feelings and as she had grown comfortable with WBL she'd be surprised how powerful the journal had become as an agent of change. Uncertainty and the risk of failure had made the transition in her teaching difficult for Helen but she knew that this was true for everyone. Her reward was to feel more in control of her teaching than she had ever before.

Helen wanted to use the WBL system but first she wanted evidence that most of her students would have access to computers. At Helen's request the faculty provided her with data on student demographics, feedback from faculty focus groups and data from the Course Experience Questionnaire, which all graduates were asked to complete following graduation. A number of graduates had commented in the CEQ that they 
felt the course was a little to full of content and rewarded memorisation. Her university had significant numbers of part time students who worked full time but the data showed that full time students were also working in increasing numbers. These students wanted, and appreciated, more flexibility in their learning. She discovered that $90 \%$ of her students would have off campus access to networked computers, and that full fee paying international students made extensive use of on campus facilities although they were widely seen as inadequate.

Helen planned to make extensive use of the university's WBL system to support teaching and learning as a result of these findings. When Helen discussed the implications of inadequate facilities, the associate dean agreed to see how the facilities could be improved.

She planned to dispense with half of the traditional lectures, replacing them with a self study guide and appropriate readings. The use of the self study materials would be supported with regular web based focused discussions taking place on alternate weeks throughout semester using the WBL system with which students had become familiar. Development of the self study guide was simplified by using a well designed and easily adapted template for learning guides and subject readers already widely in use at her university.

Helen started the redesign of the subject's assessment activities by obtaining the course accreditation details. Some of the course objectives, such as possessing the knowledge associated with working in various business professions and developing students' capabilities as creative problem solvers, would be easily incorporated into the learning activities for the subject. Effective team worker suggested a team based learning activity such as a debate and the self and peer assessment system could be used to promote teamwork and equitable contributions from students.

Some of the other course objectives surprised her. How could she get students to be inter-culturally sensitive and appreciate alternative ethical systems? When she contacted the academic development unit for advice she was given a copy of Freeman and Capper's (1999) paper on anonymous, asynchronous web based role play simulations. Reflecting on the paper, Helen saw that she would be able to address the objectives of inter-cultural sensitivity and alternative ethical systems through a role play. The role play sounded like fun and the anonymity would encourage students to step outside their own learning experiences and biases as they 
responded to various ethical dilemmas that she'd pose. The importance of the activity was reflected in the 35\% weighting it carried.

Helen wanted to base the use of these learning activities on solid evidence of effectiveness. Laurillard's (1993) book and the case studies in Alexander \& McKenzie (1998) had been important for Helen's understanding of the use of information technology in teaching. She now thought of information technology as an enabling resource whose effectiveness depended on the teaching and learning activity employed, and not on features of the technology.

Helen drew up a table for inclusion in the subject outline that mapped how each assessment task contributed to the course and subject objectives. This made it clear to the students that participation in the role play would contribute to their understanding of inter-cultural sensitivity and alternative ethical systems.

Departmental policy required a 50\% final exam in each subject to ensure the individualisation of testing. Helen felt that it was also a certain way to encourage practices characteristic of surface approaches to learning, such as rote memorisation. She was successful in negotiating a reduction to $35 \%$ for her subject as an optional assessment because she was able to demonstrate to the associate dean that the $35 \%$ role play required a considerable commitment of each student's time. The individualised nature of the activity would ensure that each student's contribution would be highly visible.

Knowing that students wanted and appreciated flexibility Helen chose to offer students a choice of assessment activities for the remaining $30 \%$. Students were required to choose one team based task (topic tracking or a web based debate for 15\%) using the use the self and peer assessment system, plus one individual task (a web based presentation and report, or a series of multiple choice quizzes for $15 \%$ ).

Helen was energised by the whole experience of re-engineering the subject. She now felt that her teaching practices and assessment tasks were aligned with the course and subject objectives and she looked forward to confirmation of Biggs' (1999) comment that 'constructive alignment makes the student themselves do the real work'. Helen had reduced her face to face teaching hours by half and much of this time would be spent facilitating students' use of the web based learning activities. The changes 
she'd introduced would allow her more flexible use of her time. Students weren't the only ones benefiting from appropriately chosen flexible learning practices.

The semester was about to start. She wondered what the students would think.

\section{Synthesis and interpretation}

The case studies demonstrate the integration of web based learning systems into teaching and learning in a number of ways. The cases start with simple, easily implemented examples of WBL systems for improving access to information and resources but with no link to assessment. They then proceed to more sophisticated applications of the features available in a WBL system including feedback and discussion with some contribution to assessment. Finally, we see integrated uses where alignment of assessment tasks with course and subject objectives is used to encourage students to take a deep approach to learning. The key transition is one the teacher makes from a teacher centred teaching practice to student centred teaching practice and is reflected in the learning tasks and the assessment strategies employed.

Phil's concerns for students in Case 1 results in better resources like the FAQ and the use of announcements to improve administration but these don't indicate student centred practice. The teacher, Phil, is still the authority and the manner in which he ran the question and answer forum reflects this. Improving efficiency is his primary goal; improving student attitudes a secondary one.

The introduction in Case 2 of a contribution to assessment reflects Phil's changing perception of what he wants students to do. The topic tracking task can be seen as a weakening of Phil's position as the arbiter of what is, and what is not, a learning resource although he still thought it necessary to check all of the contributions before awarding the participation mark. Phil's interest is more for efficiencies than for encouraging students to engage with the material in a manner that fosters learning.

In case 3, Jenny, using much the same learning task, has directly linked the task to assessment in a way that requires the students to do more than collect resources. This is alignment. They have to relate these resources to the subject's learning objectives. The students are starting to do the work of the traditional assessor. Jenny is demonstrating a greater concern for improving student learning than simply improving her own efficiency. By 
providing additional discussion forums for feedback and social chat she is showing her commitment to building a positive learning community.

Mike, Sophie and Helen are also using assessment linked learning strategies. Their motives are now focussed primarily on improving student learning without impacting their efficiency. They have gone further than Jenny by changing the subject objectives to reflect what they wanted their students to learn as well as the capabilities and values that would be expected of graduates. The self and peer assessment system makes team work more effective because students know that they will be evaluated by their peers. Free riding will decrease because it now entails significant risk.

In Case 4 Sophie faces a situation that many academics encounter - being allocated to teach a subject developed by someone else. When academics see teaching as delivering content this portability seems reasonable. But for academics, like Jenny, Mike, Sophie and Helen, subject objectives are a key to student learning that can be adapted in the process of aligning learning and assessment tasks. What will happen if a teacher with a strongly teacher centric focus was asked to teach Sophie's or Helen's subject the following semester? Ramsden (1992, p.80) alerts us to the fragility of student approaches to learning that are likely to occur from such changes.

The cases also document several other transitions. There is transition, too, in the academics' environment. Central support for the use of a WBL system is an important contribution in keeping with an environment that supports innovation. Helen is able to use the adverse impact that inadequate infrastructure could have on web based learning systems to obtain a commitment from the associate dean to see what can be done to improve the resourcing. The self and peer assessment tool, implemented on a departmental server, makes possible assessment strategies that have proved difficult to implementing in a conventional way.

Supportive colleagues can be effective agents for change, and in the case studies they make important contributions at several points. When Phil allows Jenny to observe his web based activities she is able, without risk or commitment, to observe an innovation -one of the Rogers' factors that influences the diffusion of innovation. Mike's mentoring of Sophie can be seen as contributing to the compatibility of Sophie's efforts with the departmental culture - another Rogers' characteristic. Helen's associate dean, by agreeing to look at the infrastructure issue, is doing something too often left to the individual teacher. One can see competitive advantage 
working for Helen in the teaching release she negotiated, and perhaps as well in Phil's hopes for promotion.

The faculty workload and intellectual property policies that Helen benefited from, are examples of how factors in the environment can be altered to create a climate more conducive to change. These factors, and many others, are within the purview of senior academic managers rather than academics.

A third transition occurs in the questions that each of the academics might ask when considering the use of web based learning in their subjects. Phil can easily be imagined to ask "How can I use tool X in my teaching?" In this question the focus is on the tool rather than the teaching strategy and answers that consider student outcomes may not sound like answers to the questioner. Helen, on the other hand, is driven, in part, to explore the use of WBL systems because of their appropriateness for the role playing learning activity and because students have prior experience with the tool. Her questions about the tool relate to how a particular learning activity could be implemented and supported.

A fourth transition relates to the level of evaluation. While Phil uses of end of semester surveys, and then focus groups for feedback, Jenny provides a public discussion dedicated to the sole purpose of encouraging continuous opportunities for feedback. Evaluation is so embedded in the process used by Helen, and documented in her reflective journal, that she is considering publishing her evaluation for others to use.

The fifth transition relates to the use of technology for supporting teaching, learning and assessment strategies. Benefits, in terms of learning and of efficiency, are identified at each step. As mentioned above and consistent with Rogers' competitive advantage factor, an academic's perception of her environment has a strong influence over how she approaches change. Issues with technology infrastructure, reward structures, work pressures and intellectual property will be familiar to all academics, as suggested by Rogers in his compatibility and observability factors. The ease of trialing or trialability, another factor identified by Rogers as aiding the success of an innovation, is a feature possible with WBL systems that require minimal knowledge of web authoring and programming. Similarly the complexity factor is minimised in WBL systems, Reference to these factors is made to reinforce a most important finding, that adoption of sophisticated technologies for supporting student centred, flexible approaches to teaching requires more than technical skills. 
The sixth transition relates to managing students' expectations. Phil sees that his comment about asking questions anonymously results in increased use. Jenny provides students with a feedback discussion forum explicitly for the purpose of identifying when students' expectations are being met or missed. She also explains that her innovations are in response to student feedback. Sophie responds positively to a student suggestion of providing an exemplar of the team debate assessment, realising that innovative assessment can be stressful to students if they are unsure of what is expected of them. The explicit map showing the alignment of assessment wit objectives in the last case is a very strong signal for managing students' expectations.

The final transition relates to the explicit use of assessment to motivate student effort and engagement. Phil uses WBL to improve learning outcomes through formative feedback, and his use of assessment is limited to a small participation mark. Jenny makes a stronger link with formative and summative assessment through the optional auto-corrected quizzes that were similar to final exams. But she introduces a new learning tasktopic tracking - which is assessable and makes an attempt to link class work to the real world. In the final two cases, an explicit link between each assessment task is made with qualitatively different assessments (ie. team debates, anonymous role play simulations) being utilised to achieve the stated subject and course objectives. In the last case, assessment choices are given to students.

\section{Conclusion}

We believe the most effective uses of technology supported teaching are possible when underpinned by student centred teaching practices that encourage students to adopt a deep approach to learning. In our opinion the evidence that technology supported teaching can be effective (for instance, Alexander \& McKenzie 1998) shows that the improved student outcomes relate to the teaching and learning strategies employed, and not from the medium. We use five case studies of increasingly sophisticated use of a web based learning system to illustrate a number of key transitions.

For many academics the change to student centred practice is difficult and requires extensive reflection, experiment, evaluation, uncertainty and support. For educational innovators, factors in the environment that act as barriers to mainstream academics are surmountable and the chance to achieve something significant seems to be sufficient motive for undertaking change. The mainstream academic weighs the same factors differently and will only be persuaded if the case for change is clear and 
support is available. This support needs to be technical, administrative and pedagogical and available to them in the context of their situation. The need for this support can be understood in terms of Rogers' characteristics of innovations (Rogers, 1995).

Perhaps the most significant barrier to change is the academic's own conception of teaching. If their practice is based on the view that students are, or are not, capable of university learning (students are), and that what the teacher does is relatively inconsequential, then academics will not see a need to try other approaches. If their view of teaching is that students learn because of the resources that the academic makes available (students get), the attraction of technology supported teaching strategies will centre on improvements in delivery and the quality of resources. Worthy and useful though these may be, improved learning outcomes are unlikely. When an academic's practice reflects the recognition that students create meaning for themselves, and that they do this by engaging in learning tasks that require them to demonstrate their understanding (students do), then technology can be used to dramatic effect in supporting improve student learning.

This paper touches on the development of teaching and assessment strategies, and the design of appropriate course and subject objectives, but it is not intended to be a comprehensive guide. Works by Paulsen (1995), Brown and Glasner (1999) and Toohey (1999) provide avenues for further exploration of these issues.

A major limitation of our views on facilitating the use of technology supported teaching is the scant evidence for changes like those that we discuss in the case studies being carried out at the level of the course or institution. Collis' TeleTOP implementation at the University of Twente is one such case (Collis \& De Boer 1999). For most institutions perception of the need for such an approach remains remote. Other limitations include the fragility of student approaches to learning due to decisions by academics and academic managers, and the difficulty in isolating the effects of different decisions. Whether technology supported or not, a well designed subject that aligns assessment with objectives and has well supported learning activities, may fail to encourage deep approaches to learning because students are expected to expend too much effort for too few marks. Similarly, novelty value from the efforts of an enthusiastic innovator may be the only reason for the initial positive reaction of students to a technology supported learning tool.

Our hope is that colleagues will be inspired to explore the use of WBL systems and try for themselves some of the activities presented in the case 
studies. Regardless of experience or views of teaching, benefits to teachers and students can be achieved.

\section{References}

Alexander, S. and McKenzie, J. with Geissinger, H. (1998). Evaluating IT projects for university learning: the CAUT experience. EIP study, Australian Government Publishing Service. See also http: / / www.detya.gov.au/cutsd/ publications / exsummary.html

Bassey, M. (1999). Case Study Research in Educational Settings. Buckingham: Open University Press

Biggs, J. (1999a). Teaching for Quality learning at University. Buckingham: Open University Press.

Biggs, J. (1999b). Assessing learning quality: reconciling institutional, staff and educational demands. Assessment and Evaluation in Higher Education, 21, 5-15.

Bowden, J. \& Marton, F. (1998). The University of Learning. London, Kogan Page.

Brown, S. \& Glasner, A. (Eds) (1999). Assessment Matters in Higher Education. Buckingham: Open University Press.

Clark, R. E. (1994). Media will never influence learning, Educational Technology Research and Development, 42(2).

Clark, R. E. (1983). Reconsidering research on learning from media, Review of Educational Research, 53(4).

Collis, B. \& De Boer, W. (1999). The TeleTOP Method at the University of Twente. Paper presented at ED-MEDIA, June 1999.

Chickering, A. W. \& Ehrmann, S. C. (1997). Implementing the seven principles: Technology as lever. http:/ / www.aahe.org/technology/ehrmann.htm [verified 12 Nov 2000]

Creswell, J. W. (1998). Qualitative Inquiry and Research Design: Choosing Among Five Traditions. Thousand Oaks, CA: Sage.

Entwistle, N. (1995). The use of research on student learning in quality assessment. In G. Gibbs (Ed), Improving Student Learning - Through Assessment and Evaluation. Oxford-Brookes University. [verified 12 Nov 2000] http: / / www.lgu.ac.uk/ deliberations/ocsd-pubs/islass-entwistle.html

Freeman, M. (1997). Flexibility in access, interaction and assessment: the case for web based conferencing and teaching programs, Australian Journal of Educational Technology, 13 (1), 23-39. http: / / www.ascilite.org.au/ajet/ajet13 / freeman.html

Freeman, M. \& Capper, J. (1999). Exploiting the web for education: An anonymous asynchronous role simulation, Australian Journal of Educational Technology, 15(1), 95-116. http: / / www.ascilite.org.au / ajet/ajet15/ freeman.html 
Geoghegan, W. H. (1996). Instructional technology and the mainstream: The risks of success. Mayhum Distinguished Lecture, SUNY College at Fredonia.

Goldfinch, J. (1993). Further developments in peer assessment of group projects. Assessment and Evaluation in Higher Education, 19(1), 29-35.

Gros, B. \& Spector, M. (1994). Evaluating automated instructional design systems: A complex problem. Educational Technology, 34(5/6), 37-46.

Hara, N. \& Kling, R. (1999). Student's frustration with a web-based distance education course. FirstMonday 4(12). [verified 12 Nov 2000] http: / / www.firstmonday.dk/issues/issue4_12/hara/index.html

Laurillard, D. (1993). Rethinking University Teaching: A Framework for Effective use of Educational Technology. London, Routledge.

Marton, F. \& Säljö, R. (1976). Qualitative differences in learning I: outcome and process. British Journal of Educational Psychology, 46, 115-27.

Paulsen, M. F. (1995). The Online Report on Pedagogical Techniques for ComputerMediated Communication. [verified 12 Nov 2000] http: / / www.nettskolen.com/alle/forskning/19/cmcped.html

Prosser, M. \& Trigwell, K. (1999). Understanding Learning and Teaching: The Experience of Higher Education. Buckingham: Open University Press.

Ramsden, P. (1992). Learning to teach in higher education. London, Routledge.

Reeves, T. (1994). Evaluating what really matters in computer-based education. http:/ / www.educationau.edu.au/archives/cp/reeves.htm [verified $12 \mathrm{Nov}$ 2000]

Rogers, E. M. (1995). Diffusion of Innovations. 4th ed. New York: Free Press.

Toohey, S. (1999). Designing Courses for Higher Education. Buckingham: Open University Press.

Simon Housego, Institute for Interactive Media \& Learning, University of Technology, Sydney

Mark Freeman, Faculty of Business, University of Technology, Sydney. Email: mark.freeman@uts.edu.au 